\title{
The Maker Movement: From the Development of a Theoretical Reference Framework to the Experience of DENSA Coop. Soc
}

\author{
Valentina Costa
}

\begin{abstract}
The Maker Movement, which has for years received much attention, still presents many economic, social and educational implications that are ripe for investigation. The movement's community of practice can be defined as " $a$ knowledgebuilding community" (Scardamalia and Bereiter, The Cambridge handbook of the learning sciences, pp 97-115, 2006) as cited in Martin (Martin, J Pre-Coll Eng Educ Res (J-PEER) 5(1):4, 36 2015). This apt definition, which refers to the hyper complex, connected society that engendered it, opens up new possibilities in the field of education. The main goal of this reflective paper is linked to the creation of a theoretical framework that could explain and support the movement's background. This will lead to an analysis of three different pedagogical models (Célestin Freinet, Loris Malaguzzi, Bruno Munari) that have much in common with the Maker Movement. We focused our study on the most positive traits of makers: social inclusion, democracy and the failure-positive/collaborative approach. Considering the importance of the European Union's Key Competences, our aim was to create a bridge between the "maker mindset" (Dougherty, Design, make, play, pp 9, 25-29, 2013) and these competences, in order to consider the possibility of introducing the movement into the national curriculum. The point of contact between the two can be the basis for promoting active citizenship, grounded, naturally, in the Key Competences. Subsequently, to test our analysis in the first part of our reflection, we look at the experience of DENSA (Developing Edutainment for New Skills and Attitudes) Coop. Soc.
\end{abstract}

Keywords Maker movement · Making $\cdot$ Key competences $\cdot$ Failure-positive • Social inclusion $\cdot$ Democracy $\cdot$ Collaborative learning

\footnotetext{
V. Costa $(\bowtie)$

University of Perugia, 06121 Perugia, Italy

(C) The Author(s) 2021

D. Scaradozzi et al. (eds.), Makers at School, Educational Robotics and Innovative

Learning Environments, Lecture Notes in Networks and Systems 240,

https://doi.org/10.1007/978-3-030-77040-2_18
} 


\section{Introduction. Children, Makers, Key Competences}

This paper has its roots in the work of DENSA Coop. Soc., a young social cooperative in Italy, working within the extracurricular system, whose mission has much in common with the principal features of the Maker Movement. This reflective paper considers the role of maker didactics (culture) in the development of active citizenship through the Key Competences framework.

We first looked at the social function that the maker space-a place where people create things - can fulfil. The maker space appeared not only to be a place where interpersonal relationships, social ties, business connections can develop, it also facilitates the learning of new skills (Sturges 2013).

The maker space can also stimulate the creative process, and help the individual cultivate a passion, thanks to the "playful" (Tanenbaum et al. 2013, p. 2603) approach that characterizes the movement and can be found in these labs. In addition, the paradigm of the maker space as a place that can foster social inclusion, tolerance and peer collaboration can give definition to the concept of active citizenship (another pivotal theme of democratic citizenship).

\section{Community and Participation: Makerspace and Social Inclusion}

Anderson (2012), a leading contributor to the literature on the Maker Movement, has said that society's current cultural (and fertile) structure is what has influenced and helped spread the democratic maker revolution. At the same time, it has assisted the spread of democratizing tools, experiences and customs, including: the Open Source model ("Open Source is not just an efficient innovation model-it's a belief system as powerful as democracy or capitalism for its adherents") (Anderson 2012, p. 93); the dissemination of maker spaces and Maker Faires; the launch of low-cost 3D printers (e.g., MakerBot); and the availability of tools. It should be stressed that relationships can develop within maker communities (both online and offline) based on mutual exchange, assistance and collaboration. In these settings, a maker has the opportunity to use tools (e.g., a laser cutter, a vinyl cutter, a CNC router, a CNC milling machine) to create, collaborate, form partnerships, and facilitate interoperability.

According to Tanenbaum et al. (2013), the materials needed for production already seem to suit collaborative making. Again, standardized structures and materials are functional for creating and building a knowledge-sharing system. This means that every participant is involved in the same system of values and meaning, and this helps build community, collaboration and a collective learning process (Tanenbaum et al. 2013). This is why, according to Martin (2015), the Maker Movement can be considered "a knowledge-building community," a kind of community that "works collectively to build and share new knowledge" (Martin 2015, p. 36) (like the scientific community), in a non-competitive manner (Scardamalia and Bereiter 2006). 
As a further matter, we analyzed how the maker approach can be related to social issues; and for this, Jeff Sturges and his story are an excellent case in point. At the 2013 TEDx Midwest conference, Sturges, generally considered a community idealist and a maker, presented a project taking place in the basement of the Church of The Messiah in Detroit. There, the idealist and his group had created a maker space for the local community. When describing his idea, Sturges emphasized that he was strongly motivated by social issues when starting this project. His aim was to create a space where people could connect and have an opportunity to work and spend time together. He stressed that the young people attending the space, born and raised in under protected areas of the city, found a "safe haven" in the maker space. They were aware that this new environment could open a door to their future working lives, thanks to the opportunity to learn new skills. Everyone in the film he presented talked about his or her own experience of social inclusion. One of the adolescents said that when he is focusing on designing or creating something at the maker space, time flies and he is not drawn to the usual "temptations" (Sturges 2013). These stories portray the happiness and pleasure of getting together, within a community, getting involved in creative activities in a safe and secure place. As reported by Taylor et al. (2016) the maker space can be defined as a "third place," a social space (away from the home or the workplace) that can play a pivotal role in the individual's public life.

To sum up, the maker space is a place that can offer an array of positive interactions and stimulating activities. It fosters the development of social ties and relationships, the learning of essential skills for the future, and the opportunity to create things and cultivate a hobby. The maker space should be considered a social leveller, a place where there can be no discrimination (Taylor et al. 2016).

\section{Key Competences and Active Citizenship}

The community framework and the collaborative mechanisms that characterize maker communities (in the way of Tim Berners-Lee's theorization of interoperability and Pierre Lévy's collective intelligence) seem to be compatible with the development of active citizenship. Making and the maker mind set (fostering social inclusion, democracy tolerance and collaboration) can play a crucial role in mastering the key competences. First, we examined four (of the eight) competences: on the one hand mathematical competence and competence in science, technology and engineering, digital competence (disciplinary skills), and on the other citizenship competence, cultural awareness and expression competence (cross competencies). When we consider the two disciplinary skills mentioned earlier, their encounter with the maker min set can yield surprising results. If we analyze the text of the EU Council Recommendation of 22 May 2018 on Key Competences for Lifelong Learning, many points in common emerge between disciplinary competences and the maker mind set, sparking a reflection on the potential work that can be achieved.

(Mathematical competence and competence in science, technology and engineering). "... It includes the ability to use and handle technological tools and 
machines as well as scientific data to achieve a goal or to reach an evidence-based decision or conclusion." For this reason, the European Council's guidelines clarify the importance of becoming familiar with the use of "technological tools and machines." Thus, it is natural to think of the Maker Movement and the role that tools play in the maker community; introducing the maker mind set can promote the learning of these technical practices. It is also important to remember that "experimental play" (Martin 2015 , p. 35) is the makers' usual way of doing things: a recreational perspective on technical learning. At the same time, digital competence also fits perfectly into the movement's structure. In fact, again according to the European Council's declaration (2018), attaining good digital awareness means having an interest in digital technologies and in related topics, and, hence, dealing responsibly with digital literacy and all related practical aspects (such as programming, coding and so on ... cf. Jeanette Wing and her viewpoint).

In short, the other two cross competencies, namely, citizenship competence, cultural awareness and expression competence, can be linked to the Maker Movement through its fondness for cooperative learning (team work) and the failure-positive approach. "Competence in cultural awareness and expression involves having an understanding of and respect for how ideas and meaning are creatively expressed. [...] It involves being engaged in understanding, developing and expressing one's own ideas and sense of place or role in society in a variety of ways and contexts." Thus, a positive and active outlook on the development of personal ideas is related to the maker's tendency to work on certain theoretical ideas in order to bring them into reality.

"Citizenship competence is the ability to act as responsible citizens and to fully participate in civic and social life, based on understanding of social, economic, legal and political concepts and structures, as well as global developments and sustainability." The usual dynamics of a maker space can be seen as an explanatory example of active citizenship. The very structure of the community requires a form of active citizenship that can help build shared knowledge. To sum up, these analogies can lead us to imagine certain beneficial results. For example, the maker mind set can help children learn key competences and, as a result, become active citizens.

\section{The Experience of DENSA Coop. Soc}

While reflecting on this subject, we decided to relate the Maker Movement to three different pedagogical models of the last century-Célestin Freinet, Bruno Munari, Loris Malaguzzi - to show the maker mind set's compatibility with the educational system. In this paper we will only consider the French pedagogue, Freinet. As a pragmatic teacher, Freinet always promoted a concrete, tangible form of education, and considered work to be an important ally of learning. In his view, education required experience; a technique for life (Legrand 1993). This direct (conceptual) connection is linked to Dougherty's (2012) description of a maker mind set. According to the 
latter author, a maker is a creator who plays an active role in the creative process, and exploits manual techniques.

Moreover, according to Freinet (2002), school subjects should not forgo the collaborative approach, which should be part of an internal system of sharing and interacting; each learner should be an active participant in the network. This is an early theorization of active citizenship.

Retracing the three authors' steps and rediscovering their mind sets in the light of the Maker Movement were crucial and preparatory to the study of the DENSA experience. The cooperative is profoundly connected to the Maker Movement, as is evident in its mission of inclusion, and its aim of providing learning opportunities to all. It applies the maker mind set to enhance skills and capabilities. We had an opportunity to study DENSA (and its activities) for four months (November 2018 to February 2019), analyzing the links between making skills and the learning process. In doing so, we looked at two workshop activities that aimed to introduce the maker culture to an extracurricular project: Making Culture-Our Heritage in 3D (which involved a 3D printing system) and Coding Unplugged (involving educational robotics).

The aim of Our Heritage in $3 D$ was to reflect on artistic and cultural heritage (tangible and intangible) and on territorial identity (past and present). The project appeared to be a good opportunity for participants to practice all four of the competences we considered. First, it is noteworthy that the workshop was linked to a collective reflection on the recent earthquake in the region (2016). In fact, the event caused serious damage to Perugia's Carducci-Purgotti secondary school, which later had to be demolished. The idea behind Our Heritage in $3 D$ was to invite students to think about the aftermath of the disaster, by creating 3D prototypes. In addition, the project had a specific intercultural theme (inspired by the multicultural class). Students analyzed the experience of Superkilen in Copenhagen as an example of social integration through urban design. These important topics allowed us to consider that all four of the competences co-existed harmoniously within the project. First, using Sugar CAD and other tools, participants were able to put their digital skills into practice, through 3D prototyping designs to reconstruct their local area, and also the competences of mathematics, science, technology and engineering. At the same time, the social and cultural themes of the project facilitated artistic expression and cooperative learning. Moreover, Our Heritage in 3D was related to INDIRE's Maker@Scuola project (2014), mainly because DENSA's activities were built on the same tools and software: In3dire, Sugar CAD, Raspberry Pi, OctoPrint, Cura. We also looked at 3D printing as an "emotional technology" (Guasti et al. 2017, p. 129), which allowed us to examine the project in all its complexity. According to this definition, 3D printing takes time, reflection and critical thinking. From here, we structured this complex project into four phases to allow students to master and develop the competences. First, students had an opportunity to get an idea about the subject and then analyze it in more depth. Next, they did some research on the theme and on icons, which was followed by a design phase using Sugar CAD. The final phase involved the TMI (Think, Make, Improve) approach. 


\section{Conclusions}

To sum up, the aim of our reflection on the Maker Movement was to underline how the maker mind set can foster learning, not only in individual disciplinary subjects, but also of cross-disciplinary competencies. It is interesting to note that each approach that we considered (Freinet, Munari, Malaguzzi) focuses on the fundamental importance of techniques, which can be door-openers for learners. In crossdisciplinary terms, it is essential to acquire the know-how to handle all forms of learning: "Rhetoric in the Maker Movement often focuses on skills rather than abilities" (Martin 2015). As Célestin Freinet used to say, the only educational system that can help learners to cultivate their culture and prepare them for life, is one that is based on techniques (Freinet 2002).

\section{References}

Anderson, C.: Makers. In: The New Industrial Revolution. Crown, New York (2012)

Dougherty, D.: The maker mindset. In: Design, Make, Play, pp. 25-29. Routledge (2013)

Freinet, C., Eynard, R. (eds.): La scuola del fare. In: Quaderni di Cooperazione Educativa, Junior 2002

Guasti L., Rosa A., Maker@Scuola. Stampanti 3D nella scuola dell'infanzia. sFlorence, Assopiù Editore, (2017)

LEGRAND, L.: Célestin Freinet, Prospects: the quarterly review of comparative education, vol. XXIII, no. 1/2, pp. 403-418 (1993)

Martin, L.: The promise of the maker movement for education. J. Pre-Coll. Eng. Educ. Res. (J-PEER) $\mathbf{5}(1), 4(2015)$

OJ C 189, 4.6.2018, pp. 1-13

Scardamalia, M., Bereiter, C.: Knowledge building: theory, pedagogy, and technology. In: Sawyer, R.K. (ed.), The Cambridge handbook of the learning sciences, pp. 97-115. Cambridge University Press, New York, NY (2006)

Sturges, J.: TEDx Talks. The Maker Movement: Jeff Sturges at TEDx Midwest Video file. https:// www.youtube.com/watch?v=uIXJc1JE2Y\&t=633s. Accessed 6 Jan 2014

Tanenbaum, J.G., Williams, A.M., Desjardins, A., Tanenbaum, K.: Democratizing technology: pleasure, utility and expressiveness in DIY and maker practice. In: Proceedings of the SIGCHI Conference on Human Factors in Computing Systems, pp. 2603-2612, April 2013

Taylor, N., Hurley, U., Connolly, P.: Making community: the wider role of maker spaces in public life. In: Proceedings of the 2016 CHI Conference on Human Factors in Computing Systems, 1415-1425 May 2016 
Open Access This chapter is licensed under the terms of the Creative Commons Attribution 4.0 International License (http://creativecommons.org/licenses/by/4.0/), which permits use, sharing, adaptation, distribution and reproduction in any medium or format, as long as you give appropriate credit to the original author(s) and the source, provide a link to the Creative Commons license and indicate if changes were made.

The images or other third party material in this chapter are included in the chapter's Creative Commons license, unless indicated otherwise in a credit line to the material. If material is not included in the chapter's Creative Commons license and your intended use is not permitted by statutory regulation or exceeds the permitted use, you will need to obtain permission directly from the copyright holder.

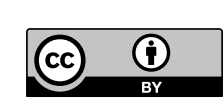

